\title{
Microstructure and Composition Evolution of a Fused Slurry Silicide Coating on MoNbTaTiW Refractory High-Entropy Alloy in High-Temperature Oxidation Environment
}

\author{
Jiesheng Han ${ }^{1,2}{ }^{\oplus}$, Bo Su ${ }^{2}$, Junhu Meng ${ }^{2, *}$, Aijun Zhang ${ }^{2}$ and Youzhi $\mathrm{Wu}^{1, *}$ \\ 1 School of Materials Science and Engineering, Lanzhou University of Technology, Lanzhou 730050, China; \\ jshan@licp.cas.cn \\ 2 State Key Laboratory of Solid Lubrication, Lanzhou Institute of Chemical Physics, \\ Chinese Academy of Sciences, Lanzhou 730000, China; bosu@licp.cas.cn (B.S.); \\ zhangaijun@licp.cas.cn (A.Z.) \\ * Correspondence: jhmeng@licp.cas.cn (J.M.); youzhiwu@lut.edu.cn (Y.W.)
}

Received: 6 July 2020; Accepted: 11 August 2020; Published: 14 August 2020

check for updates

\begin{abstract}
In this paper, the Si-20Cr-20Fe coating was prepared on MoNbTaTiW RHEA by a fused slurry method. The microstructural evolution and compositions of the silicide coating under high-temperature oxidation environment were studied. The results show that the silicide coating could effectively prevent the oxidation of the MoNbTaTiW RHEA. The initial silicide coating had a double-layer structure: a high silicon content layer mainly composed of $\mathrm{MSi}_{2}$ as the outer layer and a low silicon content layer mainly contained $\mathrm{M}_{5} \mathrm{Si}_{3}$ as the inner layer. Under high-temperature oxidation conditions, the silicon element diffused from the silicide coating to the RHEA substrate while the oxidation of the coating occurred. After oxidation, the coating was composed of an outer oxide layer and an inner silicide layer. The silicide layer moved toward the inside of the substrate, led to the increase of its thickness. Compared with the initial silicified layer, its structure did not change significantly. The structure and compositions of the oxide layer on the outer surface strongly depended on the oxidation temperature. This paper provides a strategy for protecting RHEAs from oxidation at high-temperature environments.
\end{abstract}

Keywords: silicide coating; refractory high-entropy alloys; $\mathrm{Si}-20 \mathrm{Cr}-20 \mathrm{Fe}$; high-temperature oxidation; fused slurry method

\section{Introduction}

Refractory high-entropy alloys (RHEAs) are considered to be a new generation of high-temperature materials, because they have the advantages of both high-entropy alloys (HEAs) and refractory metals (RMs), such as high-temperature strength, high hardness, and good phase stability at high temperatures [1-7]. They are mainly composed of $\mathrm{Mo}, \mathrm{Nb}, \mathrm{Ta}$, and $\mathrm{W}$, while $\mathrm{Ti}, \mathrm{Cr}, \mathrm{V}, \mathrm{Si}$, and $\mathrm{Al}$ are usually used as strengthening alloy elements [8-14]. For example, $\mathrm{Mo}_{25} \mathrm{Nb}_{25} \mathrm{Ta}_{25} \mathrm{~W}_{25}$ and $\mathrm{Mo}_{20} \mathrm{Nb}_{20} \mathrm{Ta}_{20} \mathrm{~W}_{20} \mathrm{~V}_{20}$ are two of the types of most extensively studied RHEAs [7]. The neutron diffraction analysis of those alloys after annealing at $1400{ }^{\circ} \mathrm{C}$ for $19 \mathrm{~h}$ shows that no changes have occurred to their phase structures. Their compression yield strengths are much higher than that of Inconel 718 alloy at temperatures above $800^{\circ} \mathrm{C}$. Furthermore, their yield strengths are still higher than $500 \mathrm{MPa}$ at $1200{ }^{\circ} \mathrm{C}[15,16]$. However, the poor oxidation resistance of RHEAs is a major obstacle for their use in high-temperature engineering applications, as are RMs. Successful applications of RMs in various turbines have suggested that their service lives may largely depend on their 
high-temperature oxidation resistance rather than their high-temperature mechanical properties [17]. Therefore, the improvement of their oxidation resistance is a prerequisite for the successful application of RHEAs in high-temperature oxidation environments.

The addition of anti-oxidant alloy elements is one of the strategies to improve the oxidation resistance of RHEAs, but it inevitably diminishes the mechanical properties. It is necessary to find a balance between the high-temperature mechanical properties and the oxidation resistance [18]. In the past years, more than 20 types of RHEAs have been studied to enhance their oxidation resistance through anti-oxidant alloy addition. The alloying elements enable the formation of protective oxide layers at elevated temperatures [19-23]. Gorr et al. reported two equiatomic AlCrMoTi- $\mathrm{X}(\mathrm{X}=\mathrm{Nb}$ or $\mathrm{Ta})$ RHEAs [18,24]. In their work, the RHEAs sheets were exposed to air at temperatures from $900{ }^{\circ} \mathrm{C}$ to $100{ }^{\circ} \mathrm{C}$ for $48 \mathrm{~h}$. The results showed that the mass of the RHEAs increased less than those of RMs and TaAlCrMoTi RHEA had the superior anti-oxidant property. Other studies have also showed that the addition of $\mathrm{Ti}$ and $\mathrm{Si}$ is beneficial to the oxidation resistance of RHEAs [20-22,24].

Preparing anti-oxidation coatings on surfaces is another effective method to improve the oxidation resistance of RMs, allowing them to be successfully applied in engineering applications under high-temperature oxidation environments. Among anti-oxidation coatings, silicide coatings have been widely used to protect RMs and many studies have addressed on the Si-20Cr-20Fe coating. The technical report (AFML-TR-68-210) of the Air Force Materials Laboratory (USA) opened up the possibility of protecting RMs with fused silicide coatings [25]. It suggested that the Si-20Cr-20Fe coating was very stable in air at $1360^{\circ} \mathrm{C}$, and it was considered as the best candidate for protecting niobium alloys. The Si-20Ti-10Mo and Si-20Cr-1/2B $\mathrm{B}_{4} \mathrm{Si}$ coatings were identified as better choices for tantalum and molybdenum alloys, respectively, because they can be reliably used at $1760{ }^{\circ} \mathrm{C}$. The technical report of the NASA Contract (NGR-27-003-001) characterized the microstructure of the Si-20Cr-20Fe coating on a niobium alloy [26]. The technical report (NASA TN D-7617) evaluated the protective performance of the Si-20Cr-20Fe coating on three different RMs (FS-85, C-129Y, and Cb-752) in stagnation model plasma arc tests [27]. The technical report (NASA TN contractor report 201753) reported that the Si-20Cr-20Fe coating provided very good oxidation protection for Mo-Re alloys at $1260{ }^{\circ} \mathrm{C}$ and Mach 4 in the Hypersonic Materials Environmental Test System at the NASA Langley Research Center [28]. The Si-20Cr-20Fe coating had very stable performance in a combustion atmosphere at $1360{ }^{\circ} \mathrm{C}$ and could withstand hundreds of thermal shocks. It has been successfully used as a high-temperature protective coating for niobium alloy nozzles of F100 rocket engines [29]. Sankar et al. analyzed the microstructure and composition evolution of the Si-20Cr-20Fe coating on C103 alloy during oxidation and explained the formation and oxidation resistance mechanisms of the silicide coating [30].

The aim of this paper is to explore the feasibility of the Si-20Cr-20Fe coating in improving the oxidation resistance of MoNbTaTiW RHEA. The Si-20Cr-20Fe coating was prepared on the surface of MoNbTaTiW RHEA by a fused slurry method. To show the anti-oxidation mechanism of the silicide coating, the evolution of the structure and compositions of the coating at $1000{ }^{\circ} \mathrm{C}$ and $1300{ }^{\circ} \mathrm{C}$ were studied.

\section{Materials and Methods}

MoNbTaTiW RHEA with an equimolar ratio of the elements was prepared by spark plasma sintering. Commercially available $\mathrm{Mo}, \mathrm{Nb}, \mathrm{Ta}, \mathrm{Ti}$, and $\mathrm{W}$ elemental powders were used as raw materials. The purity of all the powders was higher than $99.5 \%$. The particle size of $\mathrm{Mo}, \mathrm{Nb}, \mathrm{Ta}$, and Ti were less than $38 \mu \mathrm{m}$ and that of $\mathrm{W}$ was less than $5 \mu \mathrm{m}$. After being proportioned in an equal molar ratio, the powders were mixed by planetary ball milling for $6 \mathrm{~h}$. The mixed powders were put into a graphite mold and sintered in a spark plasma sintering furnace by vacuum hot pressing. The sintering temperature was $1500{ }^{\circ} \mathrm{C}$, the pressure was $30 \mathrm{MPa}$, and the holding time was $20 \mathrm{~min}$. The as-prepared MoNbTaTiW RHEA was used as the substrates. The MoNbTaTiW RHEA was cut into $5 \mathrm{~mm} \times 5 \mathrm{~mm} \times 20 \mathrm{~mm}$ cuboids whose surfaces were polished using 2000 mesh sandpaper and cleaned with acetone. 
A Si-20Cr-20Fe (wt.\%) coating was prepared on the RHEA cuboids by a fused slurry method. The particle size of Si powder was less than $10 \mu \mathrm{m}$, and that of $\mathrm{Cr}$ powder and Fe powder was less than $76 \mu \mathrm{m}$. The purity of those powders was higher than 99.5\%. First, the Si-20Cr-20Fe mixed powder was uniformly milled. Then, a polyethylene alcohol aqueous solution with a concentration of $4 \%$ that was used as a binder was added to the slurry. Subsequently, the RHEA cuboids were immersed in the slurry and lifted at a fixed speed, followed by drying and solidification at $80{ }^{\circ} \mathrm{C}$ in an oven. Finally, the RHEA cuboids coated with slurry were placed in a vacuum oven under a $5 \times 10^{-3} \mathrm{~Pa}$ pressure and held at $1430{ }^{\circ} \mathrm{C}$ for $1 \mathrm{~h}$ to obtain a silicide coating. Table 1 presents the compositions and properties of the as-prepared MoNbTaTiW RHEA. The flowchart of the preparation process of samples and the XRD diffraction patterns of the RHEA and the coating slurry are shown in Figure 1 . It can be seen that the RHEA has a single BCC phase and the coating slurry is a mixture of $\mathrm{Si}, \mathrm{Cr}$, and Fe.

Table 1. Chemical compositions and properties of the MoNbTaTiW RHEA.

\begin{tabular}{|c|c|c|c|c|c|c|c|c|c|}
\hline \multicolumn{5}{|c|}{ Chemical Composition, at.\% } & \multirow{2}{*}{$\begin{array}{l}\text { Density } \\
\left(\mathrm{g} / \mathrm{cm}^{3}\right)\end{array}$} & \multirow{2}{*}{$\begin{array}{l}\text { Hardness } \\
\text { (GPa) }\end{array}$} & \multirow{2}{*}{$\begin{array}{l}\text { Yield Strength } \\
\mathbf{R}_{\mathrm{p} 0.2}(\mathrm{MPa})\end{array}$} & \multirow{2}{*}{$\begin{array}{c}\text { Peak Stress } \\
\mathbf{R}_{\mathrm{mc}}(\mathrm{MPa})\end{array}$} & \multirow{2}{*}{$\begin{array}{c}\text { Fracture Strain } \\
\mathcal{E}_{\mathrm{tc}}(\%)\end{array}$} \\
\hline Mo & $\mathrm{Nb}$ & Ta & $\mathrm{Ti}$ & $\mathbf{W}$ & & & & & \\
\hline 20.0 & 18.5 & 22.3 & 21.1 & 18.1 & $11.6 \pm 0.1$ & $4.27 \pm 0.07$ & $1547 \pm 23$ & $1911 \pm 115$ & $11.5 \pm 2.6$ \\
\hline
\end{tabular}
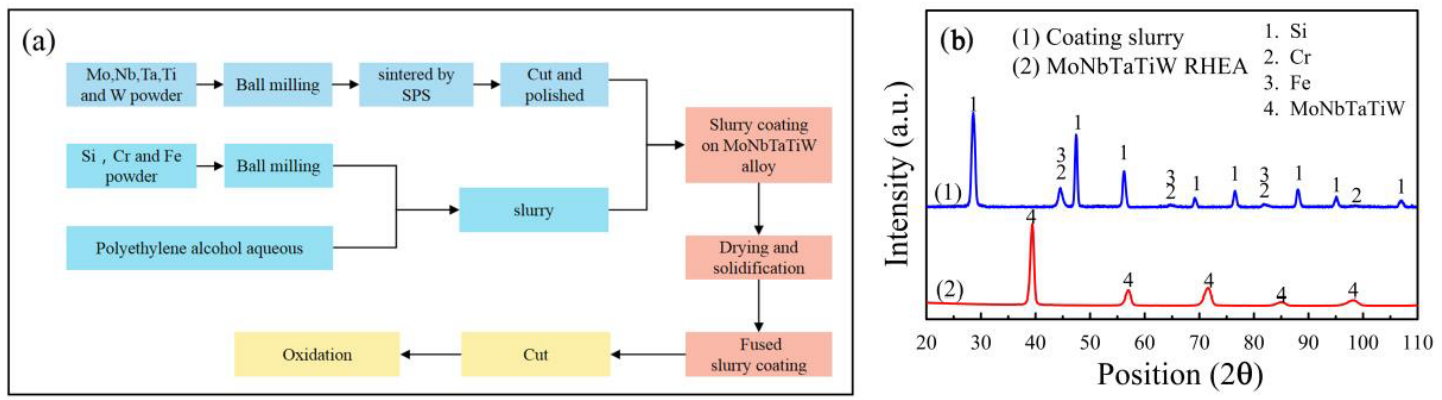

Figure 1. (a) The flowchart of the preparation process of samples and (b) XRD diffraction patterns of the coating slurry and the MoNbTaTiW RHEA.

For oxidation tests, the coated RHEA cuboids were cut into cube slices with a size of $5 \mathrm{~mm} \times 5 \mathrm{~mm} \times 5 \mathrm{~mm}$. The side surfaces of the cube slices were bare MoNbTaTiW RHEA without the silicide coating. The cube slices were placed in an alumina crucible and positioned in a box furnace. The experimental parameters of oxidation were as follows; the heating rate was $10^{\circ} \mathrm{C} / \mathrm{min}$, the oxidation temperature was set to $1000{ }^{\circ} \mathrm{C}$ and $1300^{\circ} \mathrm{C}$, the oxidation time was $1 \mathrm{~h}$, and static atmosphere.

The crystal structures were determined by X-ray diffraction (XRD, Empyrean, Almelo, The Netherlands). The surfaces and structures of the silicide coating were observed using scanning electron microscopy (SEM, JSM-5600LV, Tokyo, Japan). The chemical compositions of the samples were examined by energy dispersive spectroscopy (EDS, X-MaxN, Abingdon, Oxon, UK).

\section{Results and Discussion}

\subsection{Morphology and Microstructure of the Silicide Coating}

Figure 2a shows the surface morphology of the fused slurry silicide coating prepared on MoNbTaTiW RHEA. The coating had a rough surface on which holes and cracks can be found. Figure $2 b$ shows its XRD pattern. As can be seen, the coating is composed of disilicide $\left(\mathrm{MSi}_{2}, \mathrm{M}=\mathrm{W}\right.$, $\mathrm{Ti}, \mathrm{Mo}$, and $\mathrm{Ta})$, ternary silicide $\left(\mathrm{Cr}_{4} \mathrm{Nb}_{2} \mathrm{Si}_{5}\right)$, and lower silicide $\left(\mathrm{M}_{5} \mathrm{Si}_{3}, \mathrm{M}=\mathrm{Ti}\right.$ and $\left.\mathrm{Ta}\right)$. 

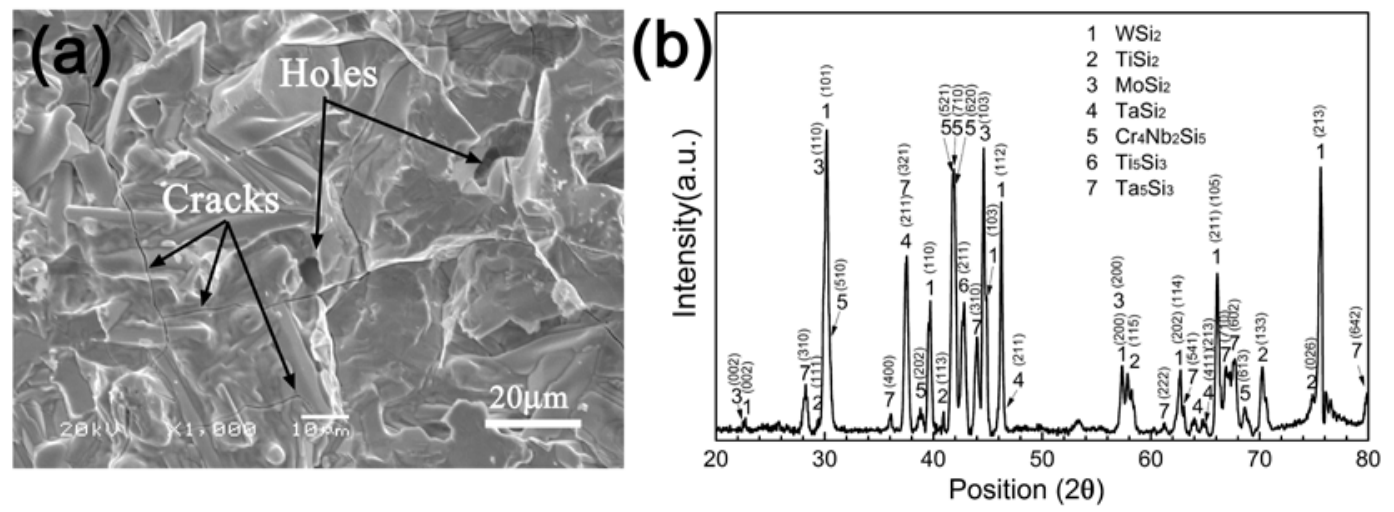

Figure 2. (a) SEM image of the surface of the silicide coating and (b) its XRD pattern.

Figure 3 shows the cross section of the silicide coating and the EDS elemental mappings of $\mathrm{Si}, \mathrm{Cr}$, and Fe. It can be seen that the silicide coating was $\sim 113 \mu \mathrm{m}$ thick. According to the distribution of silicon content, the silicide coating had a double-layer structure: a thicker outer layer that contained a higher content of silicon and a thinner inner layer that had a lower content of silicon. For example, the average atomic percentages of $\mathrm{Si}$ in regions $\mathrm{A}$ and B in Figure 3 were $66.2 \%$ and 37.9\%, respectively. However, it should be noted that the contents of both $\mathrm{Cr}$ and $\mathrm{Fe}$ in the inner layer are much higher than those in the outer layer. It also can be seen that some cracks propagated from the surface to the inner layer of the silicide coating and even to the interface between the silicide coating and the RHEA substrate.
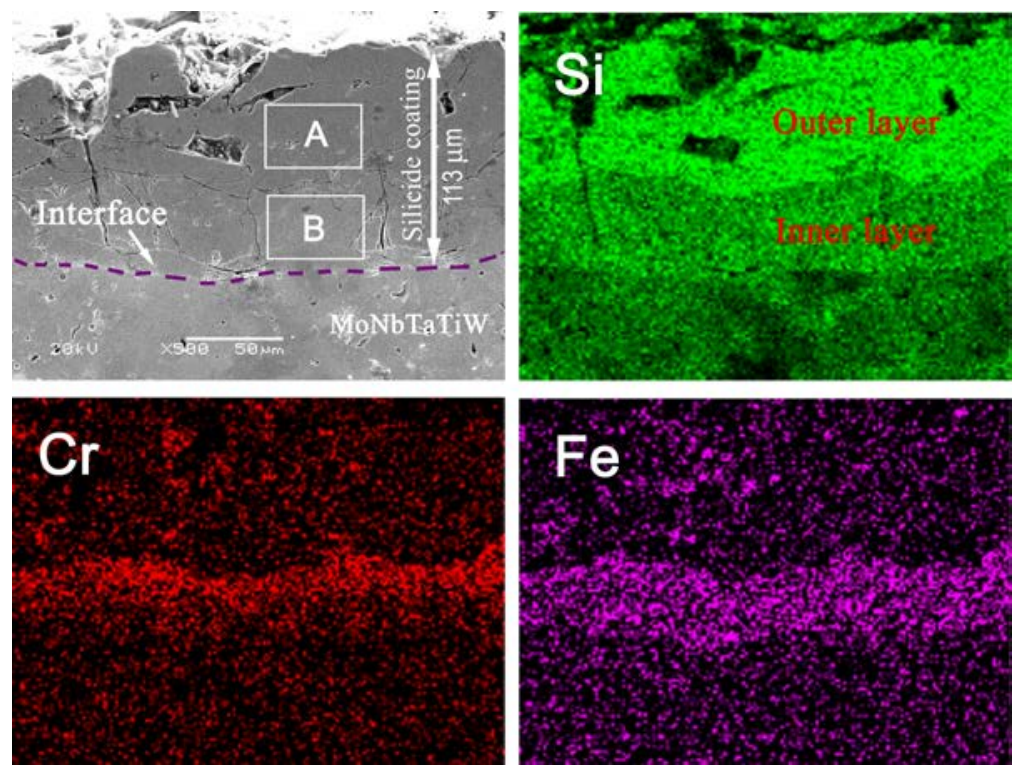

Figure 3. SEM image of the cross-section of the silicide coating and its energy dispersive spectroscopy (EDS) elemental mapping.

Previous investigations of silicide coatings on niobium alloys and tantalum alloys have shown that the outermost layers of the silicide coatings are disilicide layers, and the inner layers are low silicide layers [30-32]. In disilicide $\mathrm{MSi}_{2}$ and low silicide $\mathrm{M}_{5} \mathrm{Si}_{3}$, the theoretical percentages of $\mathrm{Si}$ atoms are $66.7 \%$ and $37.5 \%$, respectively. Therefore, it can be inferred that the outer layer of the silicide coating consisted of disilicide $\left(\mathrm{MSi}_{2}\right)$ while the inner layer was composed of lower silicide (mainly $\mathrm{M}_{5} \mathrm{Si}_{3}$ ), because silicidation and diffusion reactions occurred on the surface of the MoNbTaTiW RHEA substrate. This result is consistent with the XRD result as shown in Figure 2. 


\subsection{Oxidation Behavior of the Silicide Coating}

Figure 4 shows the morphologies of the silicide coating after oxidation at different temperatures. After oxidation at $1000{ }^{\circ} \mathrm{C}$, the surface of the silicide coating had characteristics of solidification after melting and oxide crystallization. The silicide coating became brown and was quite rough, and many cracks were generated on its surface. The uncoated side surfaces were oxidized to form a yellow oxide scale (Figure 4a). After oxidation at $1300^{\circ} \mathrm{C}$, the silicide coating became gray and an extremely thick brown oxide coating was formed on the uncoated side surfaces. The surface of the silicide coating was covered with granular crystals Figure $4 \mathrm{~b}$.

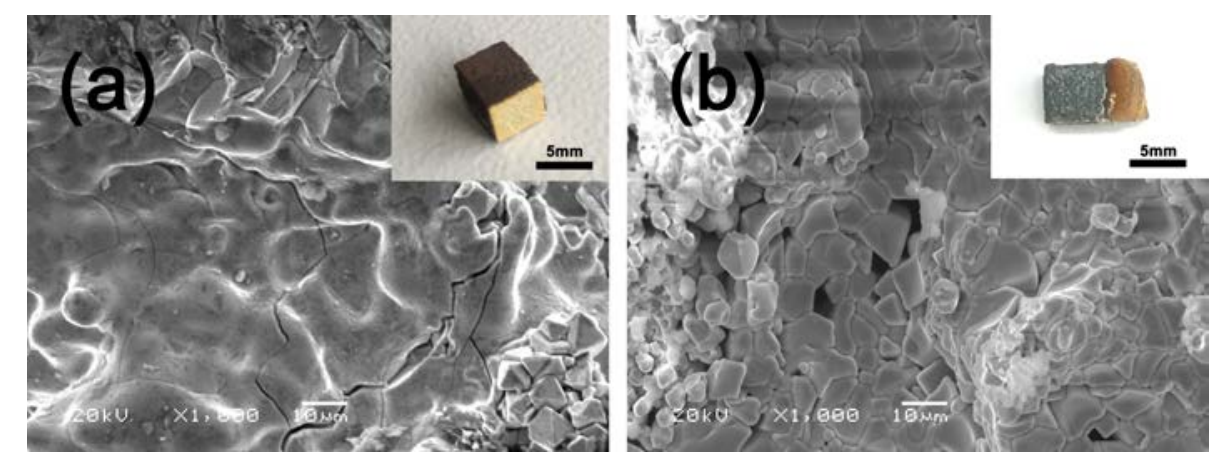

Figure 4. SEM images of the surfaces of the silicide coatings after oxidation at different temperatures: (a) $1000{ }^{\circ} \mathrm{C}$ and (b) $1300{ }^{\circ} \mathrm{C}$. Inserts are the corresponding coated samples after oxidation.

Figure 5 shows the XRD patterns of the surfaces of the silicide coating after oxidation at different temperatures. As can be seen, after oxidation at $1000{ }^{\circ} \mathrm{C}$, the surface of the coating consisted of $\mathrm{SiO}_{2}$, $\mathrm{TiO}_{2}, \mathrm{Cr}_{2} \mathrm{SiO}_{4}, \mathrm{Ta}_{0.3} \mathrm{~W}_{0.7} \mathrm{O}_{2.85}$, and $\mathrm{Ti}_{0.67} \mathrm{Nb}_{1.33} \mathrm{O}_{4}$ (Figure 5a). After oxidation at $1300{ }^{\circ} \mathrm{C}$, the surface coating was composed of $\mathrm{CrNbO}_{4}, \mathrm{SiO}_{2}, \mathrm{WO}_{3}$, and $\mathrm{Fe}_{2} \mathrm{SiO}_{4}$ (Figure 5b).
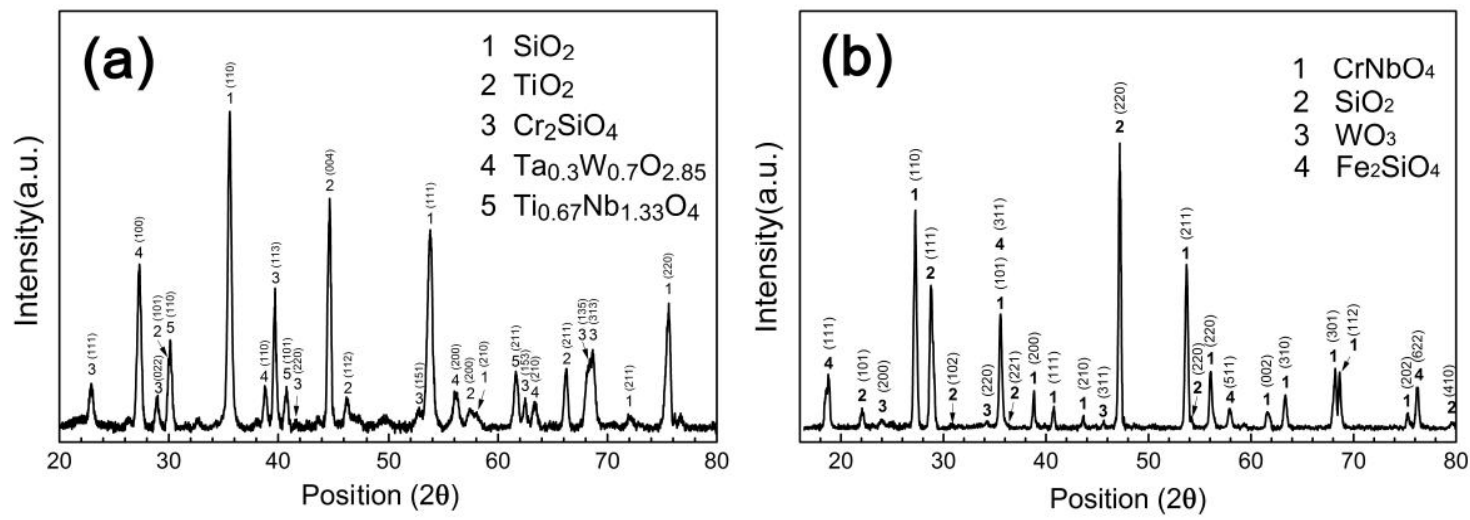

Figure 5. XRD patterns of the surfaces of the silicide coating after oxidation at (a) $1000{ }^{\circ} \mathrm{C}$ and (b) $1300{ }^{\circ} \mathrm{C}$.

Figure 6 shows the cross-section of the silicide coatings after oxidation at $1000{ }^{\circ} \mathrm{C}$ and $1300{ }^{\circ} \mathrm{C}$, and the EDS mapping of the oxidized silicide coatings is shown in Figure 7. As shown in Figure 6, all the oxidized silicide coatings had a multilayered structure. The increases in the thickness of the coating were due to the continued diffusion reaction of $\mathrm{Si}, \mathrm{Cr}$, and Fe elements to the RHEA substrate at high temperatures. All the elements of the outer layer suffered from oxidation. Both the oxidized silicide coatings maintained good integrity, but the average thickness of the coatings increased significantly during the oxidation process. The thicknesses of the silicide coating oxidized at $1000{ }^{\circ} \mathrm{C}$ was $347 \mu \mathrm{m}$ and that was about $397 \mu \mathrm{m}$ after oxidation at $1300^{\circ} \mathrm{C}$, respectively. Based on the XRD analysis result of the surfaces after oxidation (Figure 5) and the EDS mapping, the outer layer was an oxide layer and the inner layer was a silicide layer. The coating oxidized at $1300^{\circ} \mathrm{C}$ was thicker than the one oxidized at 
$100{ }^{\circ} \mathrm{C}$ because of the higher diffusion rate of silicon, and the silicon had a deeper diffusion distance at the higher oxidation temperature [33].
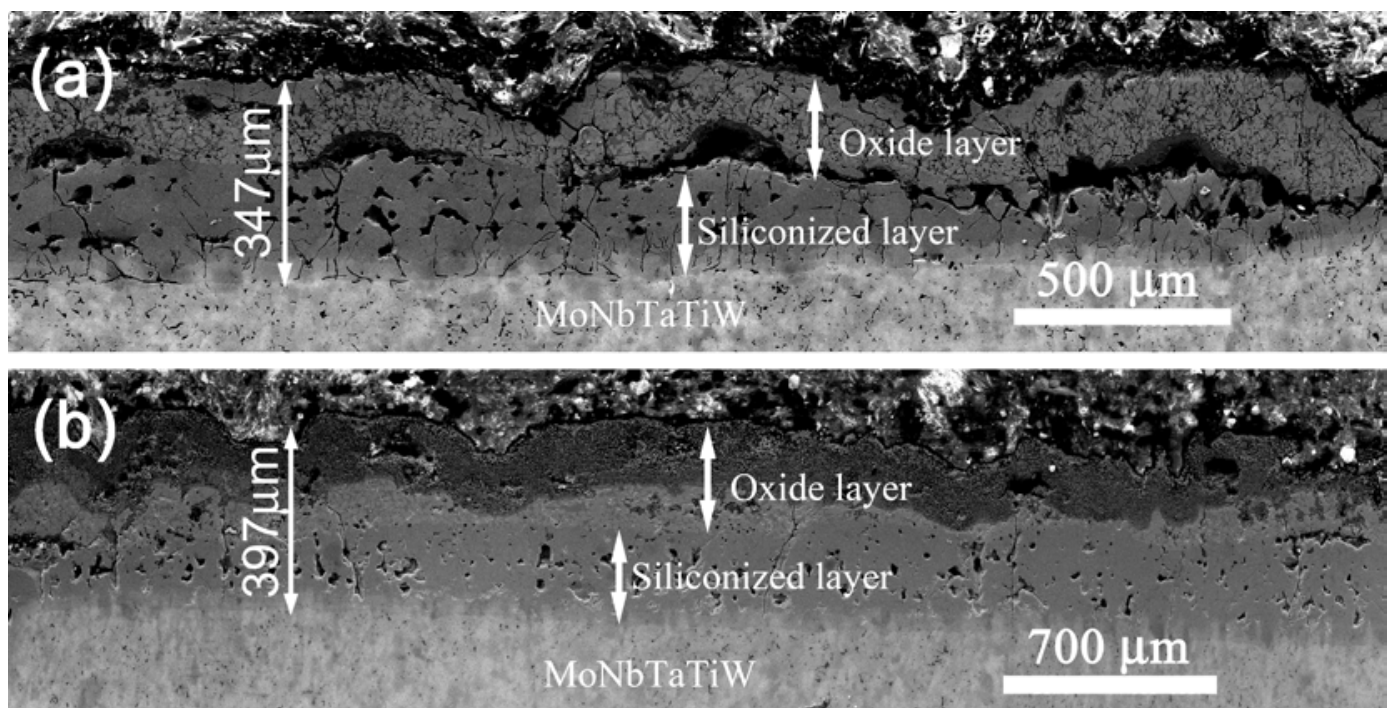

Figure 6. SEM images of the cross sections of the silicide coating after oxidation at (a) $1000{ }^{\circ} \mathrm{C}$ and (b) $1300{ }^{\circ} \mathrm{C}$.
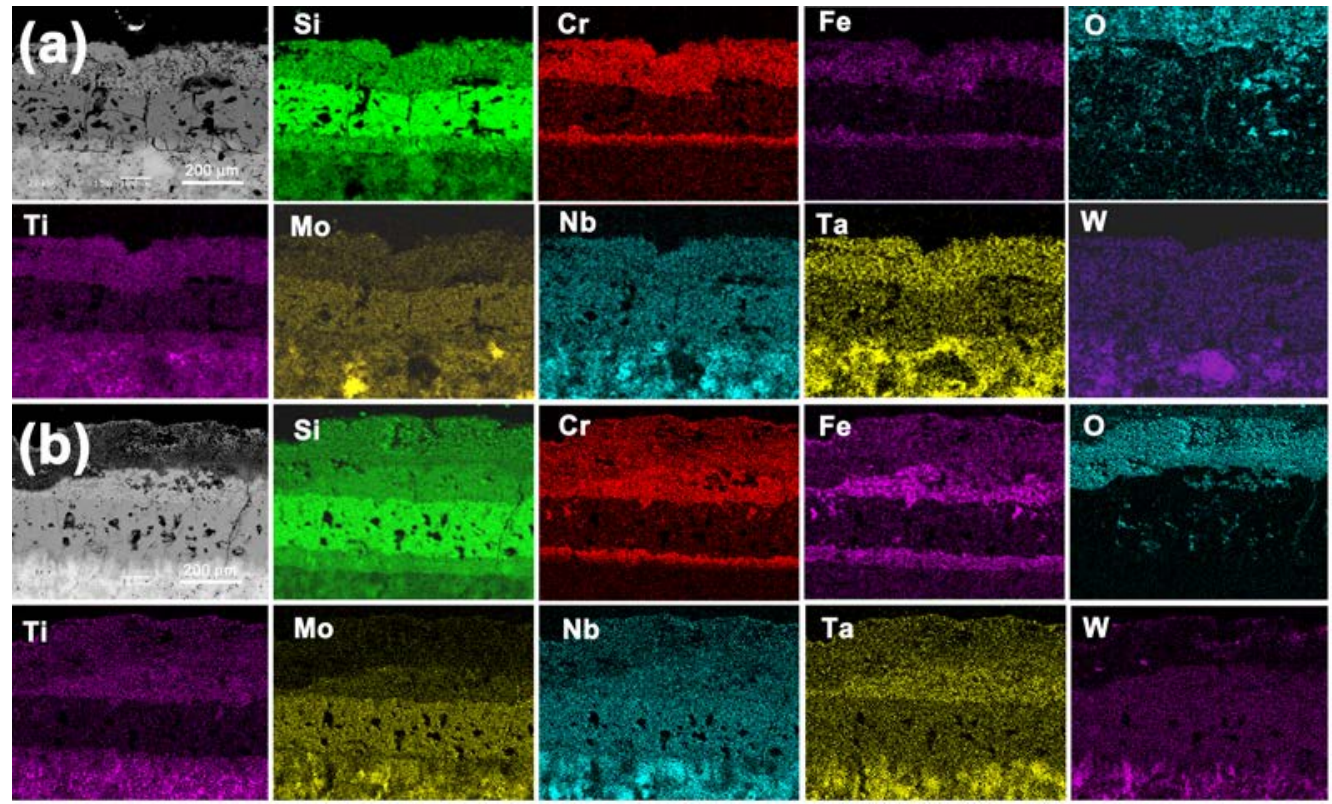

Figure 7. EDS mappings of the cross section of the silicide coating after oxidation at (a) $1000{ }^{\circ} \mathrm{C}$ and (b) $1300{ }^{\circ} \mathrm{C}$.

However, there were significant differences in the structures of the coatings after oxidation at $1000{ }^{\circ} \mathrm{C}$ and $1300^{\circ} \mathrm{C}$. Figure 6 a shows that the oxide layer exhibited a bulge phenomenon, and a gap appeared between the oxide and silicide layer after oxidation at $1000^{\circ} \mathrm{C}$. Many holes and cracks were found in the silicide layer. The cracks were originated from the interface between the silicide and oxide layers and terminated at the interface between the silicide layer and REHA substrate. According to the XRD analysis of the coating surface, the oxide scale was composed of silicon dioxide and complex metal oxides. The swelling of the oxide layer may have been caused by volume expansion during 
oxidation. The pores formed in the silicide layer were resulted from the diffusion of a large number of silicon atoms into the RHEA substrate [34].

After oxidation at $1300^{\circ} \mathrm{C}$, although the thickness of the coating increased, it still had a double-layer structure containing oxide and silicide layers, as shown in Figure 6b. Compared with the coating oxidized at $1000{ }^{\circ} \mathrm{C}$, there was no gap existed between the oxide and silicide layers, though there are also many holes and cracks were formed in the silicide layer. According to the XRD analysis of the outer surface of the coating, the oxide layer mainly consisted of complete oxides of silicon and other metal elements, but no oxides of Mo and Ta were detected. The complete oxidation of the metal and silicon could cause a significant increase in the oxide layer volume, whereas the volatilization of some oxides (such as $\mathrm{MoO}_{3}$ ) could cause the loss of the oxide layer and reduce the volume [34]. Consequently, the volume of the oxide layer was basically the same as that of the initial silicide layer. Therefore, no bulge phenomenon or cracks appeared between the oxide layer and the silicide layer.

Comparing Figures 4 and 7, the silicon element diffused into the MoNbTaTiW RHEA substrate at high temperatures, and the siliconized layer moved toward the substrate. The double-layer structure of the siliconized layer oxidized at $1000^{\circ} \mathrm{C}$ and $1300{ }^{\circ} \mathrm{C}$ was the same as the structure of the initial siliconized layer, containing an outer high silicon content layer and an inner low silicon content layer. However, there were significant differences in the oxygen content and structure of the oxide layer after oxidation at different temperatures. The oxide layer had a single-layer structure at $1000{ }^{\circ} \mathrm{C}$ and a double-layer structure at $1300^{\circ} \mathrm{C}$. The distributions of $\mathrm{Si}, \mathrm{Cr}$, and Fe were significantly different. The outermost layer had a relatively high oxygen content at the higher oxidation temperature. It is worth noting that the contents of $\mathrm{Cr}$ and $\mathrm{Fe}$ in the siliconized layer with a low content of silicon were significantly higher than those in the siliconized layer with a high content of silicon. Some $\mathrm{Cr}$ and Fe elements spread to the RHEA substrate with the Si, but at a much lower diffusion rate than that of the Si element.

According to the above analysis, the initial silicide coating had a two-layer structure. After oxidation at $1000{ }^{\circ} \mathrm{C}$, the coating had a three-layer structure of which two layers were silicide layers and one layer was an oxide layer. After oxidation at $1300{ }^{\circ} \mathrm{C}$, the coating had four layers: two were silicide layers and two were oxide layers. Figure 8 shows a structural diagram of the coating in these three states. Based on the differences in the silicon and oxygen contents in each layer, the four layers were labeled as L1, L2, L3, and L4, where L1 represents the low silicon content siliconized layer combined with the substrate, L2 represents the high silicon content siliconized layer, L3 represents the low-oxygen-content oxide layer, and L4 represents the complete oxide layer.
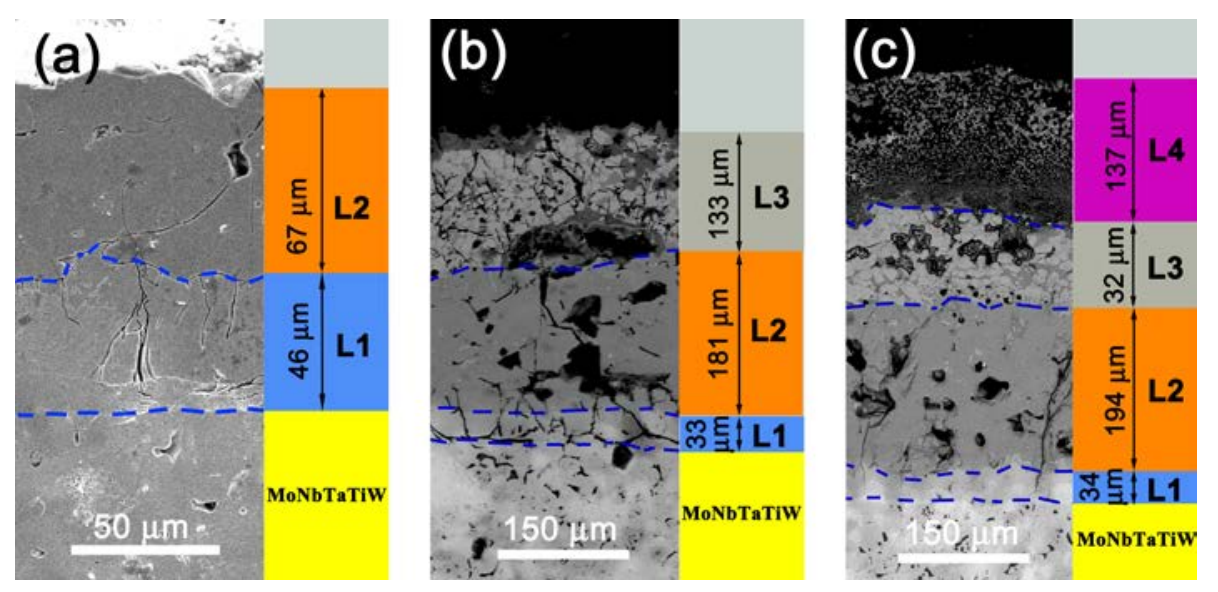

Figure 8. SEM images of the cross section of the coatings in different states: (a) initial silicide coating, (b) oxidized at $1000^{\circ} \mathrm{C}$, and (c) oxidized at $1300{ }^{\circ} \mathrm{C}$.

As a transition layer between the substrate and the coating, the thickness of the low silicon content silicide layer (L1) seemed not to have a significant correlation with the diffusion temperature and time. 
The average thickness of the L1 layer in the initial coating was $\sim 46 \mu \mathrm{m}$, and decreased to approximately $33 \mu \mathrm{m}$ and $34 \mu \mathrm{m}$ after oxidation at $1000{ }^{\circ} \mathrm{C}$ and $1300^{\circ} \mathrm{C}$, respectively. Thus, during the oxidation process, silicon continued to diffuse into the substrate, and the thickness of the siliconized layer (L2) with a high silicon content are more than doubled. The average thickness of the L2 layer of the initial coating was about $67 \mu \mathrm{m}$, and those of the L2 layers after oxidation at $1000^{\circ} \mathrm{C}$ and $1300{ }^{\circ} \mathrm{C}$ were about $181 \mu \mathrm{m}$ and $194 \mu \mathrm{m}$, respectively. According to Figure 8, it is obvious that the thickness of the oxide layer (L3 and L4) was related to the oxidation temperature, and the oxide layer became thicker at higher temperatures. After oxidation at $1000{ }^{\circ} \mathrm{C}$, the average thickness of the oxide layer L3 was about $133 \mu \mathrm{m}$. After oxidation at $1300{ }^{\circ} \mathrm{C}$, the average thickness of the oxide layer was $\sim 169 \mu \mathrm{m}$, which the average thickness of the fully oxidized layer L4 was about $137 \mu \mathrm{m}$ and that of the L3 layer was about $32 \mu \mathrm{m}$.

Table 2 summarizes the contents of the metal elements, silicon, and oxygen and possible phases existed in the L1, L2, L3, and L4 layers shown in Figure 8. The silicon content in L1 and L2 had specific values. In the L1 layer, the ratio of the total number of moles of metal elements to that of silicon atoms was about 5:3, while the ratio was about 1:2 in the L2 layer. The compositions of L2 in Figure 8a was disilicides of various metals, which is in consistent with the XRD pattern in Figure $2 b$. Therefore, it can be concluded that L2 with a high silicon content was composed of metal disilicides. Some studies have shown that the silicide of the transition layer was $\mathrm{M}_{5} \mathrm{Si}_{3}[25-30,34]$. In this work, the atomic ratio of metals to silicon in the L1 layer was basically the same as that of $\mathrm{M}_{5} \mathrm{Si}_{3}$, indicating that the silicide in the L1 layer was $\mathrm{M}_{5} \mathrm{Si}_{3}$. According to the analysis by EDS (see Table 2), L3 consisted of complex metal oxides and silicon dioxide. L4 consisted of complete oxides of silicon and metal elements. In L4 layer, because silicon and all the metal elements were completely oxidized, it had the highest oxygen content.

Table 2. Relative contents of metal, silicon, and oxygen in the different layers measured by EDS, and possible phases for the three states: initial silicide coating, oxidized at $1000{ }^{\circ} \mathrm{C}$, and oxidized at $1300{ }^{\circ} \mathrm{C}$.

\begin{tabular}{|c|c|c|c|c|c|c|c|c|c|c|}
\hline \multirow[t]{2}{*}{ Layer } & \multicolumn{3}{|c|}{$\begin{array}{l}\text { Initial Silicide } \\
\text { Coating }\end{array}$} & \multicolumn{3}{|c|}{ Oxidized at $1000^{\circ} \mathrm{C}$} & \multicolumn{3}{|c|}{ Oxidized at $1300^{\circ} \mathrm{C}$} & \multirow[t]{2}{*}{ Possible Phase } \\
\hline & $\mathbf{M}$ & $\mathrm{Si}$ & $\mathrm{O}$ & $\mathbf{M}$ & $\mathrm{Si}$ & $\mathbf{O}$ & $\mathbf{M}$ & $\mathrm{Si}$ & $\mathbf{O}$ & \\
\hline L1 & 62.2 & 37.8 & - & 58.1 & 41.9 & - & 59.2 & 40.8 & - & \multirow{4}{*}{$\begin{array}{c}\mathrm{M}_{5} \mathrm{Si}_{3} \\
\mathrm{MSi}_{2} \\
\mathrm{SiO}_{2}, \mathrm{Ti}_{2} \mathrm{O}, \mathrm{Cr}_{2} \mathrm{SiO}_{4} \\
\mathrm{Ta}_{0.3} \mathrm{~W}_{0.7} \mathrm{O}_{2.85}, \mathrm{Ti}_{0.6} \mathrm{TNb}_{1.33} \mathrm{O}_{4} \\
\mathrm{SiO}_{2}, \mathrm{WO}_{3}, \mathrm{CrNbO}_{4}, \mathrm{Fe}_{2} \mathrm{SiO}_{4}\end{array}$} \\
\hline $\mathrm{L} 2$ & 33.8 & 66.2 & - & 34.2 & 65.8 & - & 34.6 & 65.4 & - & \\
\hline L3 & - & - & - & 31.3 & 48.1 & 20.6 & 56.9 & 38.8 & 4.3 & \\
\hline L4 & - & - & - & - & - & - & 14.3 & 18.1 & 67.6 & \\
\hline
\end{tabular}

Note: $\mathrm{M}$ is the sum of the atomic ratios of all the metal elements.

\subsection{Evolution of the Structure and Compositions of Silicide Coating during the Oxidation Process}

Figure 9 shows a schematic diagram of the structure and composition evolution of the Si-20Cr-20Fe coating during preparation and oxidation. Based on the analysis in Sections 3.1 and 3.2, in the initial silicide coating and the coatings after oxidation at $100{ }^{\circ} \mathrm{C}$ and $1300{ }^{\circ} \mathrm{C}, \mathrm{L} 1$ was $\mathrm{M}_{5} \mathrm{Si}_{3}, \mathrm{~L} 2$ was $\mathrm{MSi}_{2}$, $\mathrm{L} 3$ was a complex oxide layer containing $\mathrm{SiO}_{2}$ and metal oxides, and $\mathrm{L} 4$ was a complete oxide layer that was composed of $\mathrm{SiO}_{2}$ and metal oxides. 


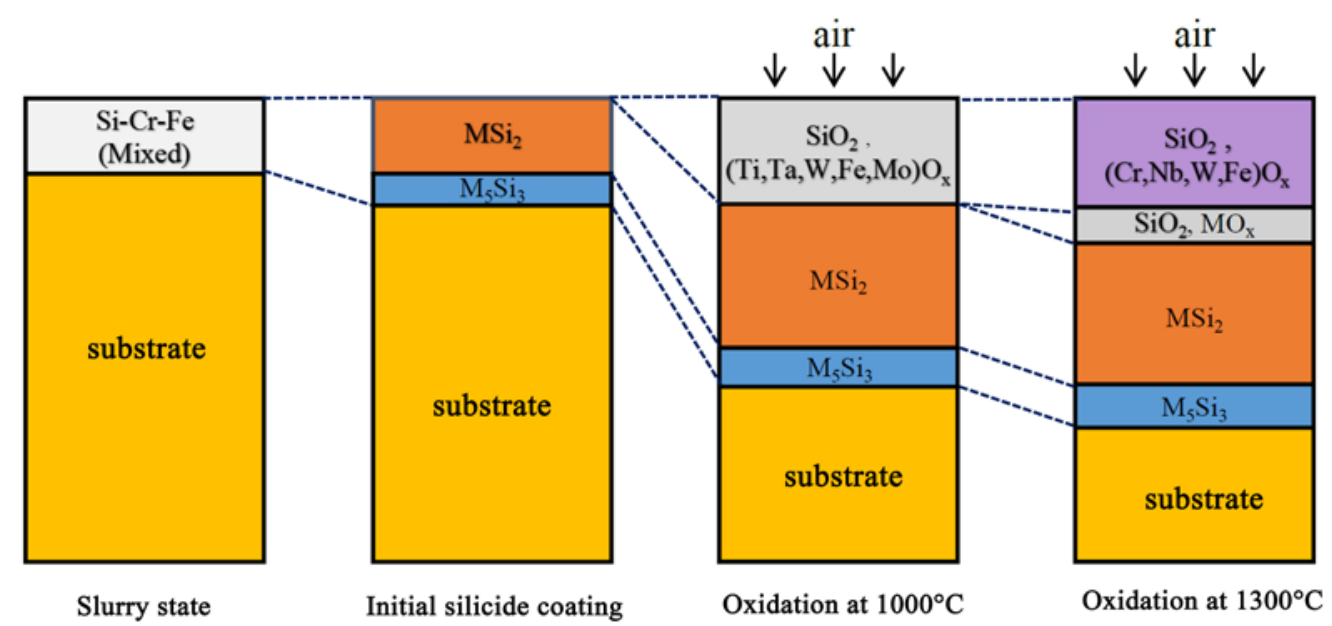

(a)

(b)

(c)

(d)

Figure 9. Schematic diagram of the evolution of the structure and compositions of the silicide coating during the preparation and oxidation processes: (a) slurry state, (b) initial silicide coating, (c) oxidized at $1000{ }^{\circ} \mathrm{C}$, and $(\mathbf{d})$ oxidized at $1300{ }^{\circ} \mathrm{C}$.

At $1430{ }^{\circ} \mathrm{C}$, the MoNbTaTiW RHEA substrate reacted with the molten Si-20Cr-20Fe slurry to form a double-layered silicide coating (Figure $9 a, b$ ). This silicidation reaction was quite complicated, all the metal elements including $\mathrm{Nb}, \mathrm{Mo}, \mathrm{Ta}, \mathrm{Ti}, \mathrm{W}, \mathrm{Cr}$, and Fe participated the reaction. Samosonov et al. established the relationship between the enthalpies of silicide formation and the silicon content, suggesting that for each metal atom, the enthalpy of silicide formation increased with increasing silicon content. It indicated that the silicide tended to bind more silicon and disilicide had the best stability [35]. Therefore, the surface of the initial silicide coating contained enough silicon atoms to form a disilicide layer and the reaction layer existed in the form of $\mathrm{M}_{5} \mathrm{Si}_{3}$ at the interface. The difference of the Gibbs free energies between MSi2 and $1 / 5 \mathrm{M}_{5} \mathrm{Si}_{3}(\mathrm{M}=\mathrm{Ta}$ and $\mathrm{Ti})$ was very smaller than those of other elements [35]. This may lead to the appearance of $\mathrm{Ti}_{5} \mathrm{Si}_{3}$ and $\mathrm{Ta}_{5} \mathrm{Si}_{3}$ in the silicide coating. The silicide of Fe could not be detected by XRD. $\mathrm{Nb}, \mathrm{Cr}$, and $\mathrm{Si}$ formed a ternary silicide $\mathrm{Cr}_{4} \mathrm{Nb}_{2} \mathrm{Si}_{5}$ whose silicon content was between those of $\mathrm{MSi}_{2}$ and $\mathrm{M}_{5} \mathrm{Si}_{3}$. During the oxidation process of the silicide coating at high-temperature oxidation environment (Figure 9c,d), the silicon element diffused into the RHEA substrate, making the silicided layer move toward the substrate. With the increasing temperature, the degree of oxidation of metal elements was more complete and the oxide layer became thicker, and the oxide layer evaluated to a double-layer structure after oxidation at $1300{ }^{\circ} \mathrm{C}$. There were no significant differences in the thickness, structure, and chemical compositions of the silicide layer.

\section{Conclusions}

(1) The Si-20Cr-20Fe coating was prepared on the surface of MoNbTaTiW RHEA by a fused slurry method. The initial silicide coating had a double-layer structure containing an outer layer of $\mathrm{MSi}_{2}$ and an inner layer of $\mathrm{M}_{5} \mathrm{Si}_{3}$.

(2) Under high-temperature oxidation conditions, the silicon element diffused from the silicide coating to the RHEA substrate while the oxidation of the coating occurred. After oxidation, the coating was composed of an outer oxide layer and an inner silicide layer. The silicide layer with a double-layer structure moved toward the substrate, led to the increase of its thickness.

(3) Compared with the initial silicide layer, the basic structure of silicide layer did not change significantly after oxidation. The structure and compositions of the oxide layer on the outer surface strongly depended on the oxidation temperature. 
Author Contributions: J.H.: Conceptualization, Methodology, Investigation, Data curation, Writing—original draft. B.S.: Validation, Formal analysis, Writing-review \& editing. J.M.: Resources, Supervision, Funding acquisition. A.Z.: Validation, Data curation. Y.W.: Validation, Formal analysis, Re-sources, Writing-review \& editing, Supervision. All authors have read and agreed to the published version of the manuscript.

Funding: This research was funded by a grant from Major Programs of the Chinese Academy of Sciences during the 13th Five-Year Plan Period.

Conflicts of Interest: The authors declare that they have no known competing financial interests or personal relationships that could have appeared to influence the work reported in this paper.

\section{References}

1. Tsai, M.H.; Yeh, J.W. High-Entropy Alloys: A Critical Review, Mater. Res. Lett. 2014, 2, 107-123. [CrossRef]

2. Gao, M.C. Progress in High-Entropy Alloys. JOM 2014, 66, 1964-1965. [CrossRef]

3. Torralba, J.M.; Alvaredo, P.; García-Junceda, A. High-entropy alloys fabricated via powder metallurgy. A critical review. Powder Metall. 2019, 62, 84-114. [CrossRef]

4. Melnick, A.B.; Soolshenko, V.K. Thermodynamic design of high-entropy refractory alloys. J. Alloys Compd. 2017, 694, 223-227. [CrossRef]

5. Yao, H.W.; Qiao, J.W.; Hawk, J.A.; Zhou, H.F.; Chen, M.W.; Gao, M.C. Mechanical properties of refractory high-entropy alloys: Experiments and modelling. J. Alloys Compd. 2017, 696, 1139-1150. [CrossRef]

6. Gao, M.C.; Carney, C.S.; Doğan, Ö.N.; Jablonksi, P.D.; Hawk, J.A.; Alman, D.E. Design of Refractory High-Entropy Alloys. JOM 2015, 67, 2653-2669. [CrossRef]

7. Senkov, O.; Isheim, D.; Seidman, D.; Pilchak, A. Development of a Refractory High Entropy Superalloy. Entropy 2016, 18, 102. [CrossRef]

8. Park, J.M.; Kang, J.W.; Lee, W.H.; Lee, S.Y.; Min, S.H.; Ha, T.K.; Park, H.K. Preparation of spherical WTaMoNbV refractory high entropy alloy powder by inductively-coupled thermal plasma. Mater. Lett. 2019, 255, 126513. [CrossRef]

9. Dobbelstein, H.; Gurevich, E.L.; George, E.P.; Ostendorf, A.; Laplanche, G. Laser metal deposition of compositionally graded TiZrNbTa refractory high-entropy alloys using elemental powder blends. Addit. Manuf. 2019, 25, 252-262. [CrossRef]

10. Chen, S.Y.; Tong, Y.; Tseng, K.K.; Yeh, J.W.; Poplawsky, J.D.; Wen, J.G.; Gao, M.C.; Kim, G.; Chen, W.; Ren, Y.; et al. Phase transformations of HfNbTaTiZr high-entropy alloy at intermediate temperatures. Scr. Mater. 2019, 158, 50-56. [CrossRef]

11. Han, Z.D.; Luan, H.W.; Liu, X.; Chen, N.; Li, X.Y.; Shao, Y.; Yao, K.F. Microstructures and mechanical properties of Ti NbMoTaW refractory high-entropy alloys. J. Mater. Eng. A 2018, 712, 380-385. [CrossRef]

12. Senkov, O.N.; Miracle, D.B.; Chaput, K.J.; Couzinie, J.P. Development and exploration of refractory high entropy alloys-A review. J. Mater. Res. 2018, 33, 3092-3128. [CrossRef]

13. Senkov, O.N.; Gorsse, S.; Miracle, D.B. High temperature strength of refractory complex concentrated alloys. Acta Mater. 2019, 175, 394-405. [CrossRef]

14. Sheikh, S.; Bijaksana, M.K.; Motallebzadeh, A.; Shafeie, S.; Lozinko, A.; Gan, L.; Tsao, T.K.; Klement, U.; Canadinc, D.; Murakami, H.; et al. Accelerated oxidation in ductile refractory high-entropy alloys. Intermetallics 2018, 97, 58-66. [CrossRef]

15. Senkov, O.N.; Wilks, G.B.; Miracle, D.B.; Chuang, C.P.; Liaw, P.K. Refractory high-entropy alloys. Intermetallics 2010, 18, 1758-1765. [CrossRef]

16. Senkov, O.N.; Wilks, G.B.; Scott, J.M.; Miracle, D.B. Mechanical properties of Nb25Mo25Ta25W25 and V20Nb20Mo20Ta20W20 refractory high entropy alloys. Intermetallics 2011, 19, 698-706. [CrossRef]

17. Gasson, P. Encyclopedia of Aerospace Engineering. In Materials Technology Aeronaut; Cambridge University Press: Cambridge, UK, 2016; Volume 116, pp. 326-328. [CrossRef]

18. Gorr, B.; Mueller, F.; Christ, H.J.; Chen, H.; Kauffmann, A.; Schweiger, R.; Szabó, D.V.; Heilmaier, M. Development of Oxidation Resistant Refractory High Entropy Alloys for High Temperature Applications: Recent Results and Development Strategy. In TMS 2018 147th Annual Meeting Exhibition Supplemental Proceedings; The Minerals, Metals \& Materials Series; Springer: Cham, Switzerland, 2018. [CrossRef]

19. Zhang, P.; Li, Y.; Chen, Z.; Zhang, J.; Shen, B. Oxidation response of a vacuum arc melted NbZrTiCrAl refractory high entropy alloy at $800-1200{ }^{\circ} \mathrm{C}$. Vacuum 2019, 162, 20-27. [CrossRef] 
20. Kanyane, L.R.; Popoola, A.P.; Malatji, N. Development of spark plasma sintered TiAlSiMoW multicomponent alloy: Microstructural evolution, corrosion and oxidation resistance. Results Phys. 2019, 12, 1754-1761. [CrossRef]

21. TTsao, K.; Yeh, A.C.; Kuo, C.M.; Murakami, H. High Temperature Oxidation and Corrosion Properties of High Entropy Superalloys. Entropy 2016, 18, 62. [CrossRef]

22. Senkov, O.N.; Senkova, S.V.; Dimiduk, D.M.; Woodward, C.; Miracle, D.B. Oxidation behavior of a refractory NbCrMo0.5Ta0.5TiZr alloy. J. Mater. Sci. 2012, 47, 6522-6534. [CrossRef]

23. Liu, C.M.; Wang, H.M.; Zhang, S.Q.; Tang, H.B.; Zhang, A.L. Microstructure and oxidation behavior of new refractory high entropy alloys. J. Alloys Compd. 2014, 583, 162-169. [CrossRef]

24. Gorr, B.; Mueller, F.; Christ, H.-J.; Mueller, T.; Chen, H.A.; Kauffmann, M. Heilmaier: High temperature oxidation behavior of an equimolar refractory metal-based alloy 20Nb-20Mo-20Cr-20Ti-20Al with and without Si addition. J. Alloys Compd. 2016, 688, 468. [CrossRef]

25. Priceman, S.; Sama, L. Technical Report TR-68-210, Development of Fused Slurry Silicide Coatings for the Elevated Temperature Oxidation Protection of Columbium and Tantalum Alloys. 1968. Available online: https://core.ac.uk/display/109028321 (accessed on 5 July 2020).

26. Griffiths, V. Technical Report NGR-27-003-001, A Metallographic Evaluation of Some Coated Columbium Alloys, NASA. 1972. Available online: https://ntrs.nasa.gov/archive/nasa/casi.ntrs.nasa.gov/19720022815.pdf (accessed on 7 August 2013).

27. Levine, S.R.; Merutka, J.P. Technical Report TN D-7617, Performance of Coated Columbium ad Tantalum Alloys in Plasma Arc Reentry Simulation Tests, NASA. 1974. Available online: https://ntrs.nasa.gov/archive/ nasa/casi.ntrs.nasa.gov/19740015000.pdf (accessed on 3 September 2013).

28. Glass, D.E. Technical Report 201753, Oxidation and Emittance Studies of Coated Mo-Re, NASA. 1997. Available online: https://ntrs.nasa.gov/archive/nasa/casi.ntrs.nasa.gov/19980000283.pdf (accessed on 7 September 2013).

29. Stechman, C.; Lawson, C. Historical Evolution of the Space Shuttle Primary and Vernier Reaction Control Rocket Engine Designs. In Proceedings of the 42nd AIAA/ASME/SAE/ASEE Joint Propulsion Conference \& Exhibit, Sacramento, CA, USA, 9-12 July 2006. [CrossRef]

30. Sankar, M.; Prasad, V.V.S.; Baligidad, R.G.; Alam, M.Z.; Das, D.K.; Gokhale, A.A. Microstructure, oxidation resistance and tensile properties of silicide coated Nb-alloy C-103. Mater. Sci. Eng. A 2015, 645, 339-346. [CrossRef]

31. Majumdar, S.; Sengupta, P.; Kale, G.B.; ISharma, G. Development of multilayer oxidation resistant coatings on niobium and tantalum. Surf. Coat. Tech. 2006, 200, 3713-3718. [CrossRef]

32. Goward, G.W. Protective Coatings-Purpose, Role, and Design. Mater. Sci. Technol. 1986, 2, $194-200$. [CrossRef]

33. Novak, M.D.; Levi, C.G. Oxidation and Volatilization of Silicide Coatings for Refractory Niobium Alloys. In Proceedings of the ASME 2007 International Mechanical Engineering Congress and Exposition. Advances in Aerospace Technology, Seattle, DC, USA, 11-15 November 2007; pp. 261-267. [CrossRef]

34. Mueller, A.; Ge, W.; Rapp, R.A.; Courtright, E.L.; Kircher, T.A. Oxidation Behavior of Tungsten and Germanium-Alloyed Molybdenum Disilicide Coatings. Mater. Sci. Eng. A 1992, 155, 199-207. [CrossRef]

35. Samsonov, G.V.; Vinitskii, I.M. Handbook of Refractory Compounds; Plenum: New York, NY, USA, 1980.

(C) 2020 by the authors. Licensee MDPI, Basel, Switzerland. This article is an open access article distributed under the terms and conditions of the Creative Commons Attribution (CC BY) license (http://creativecommons.org/licenses/by/4.0/). 